\title{
REENGENHARIA EM MÁQUINAS DE BOMBEAMENTO DE CONCRETO PARA A INDÚSTRIA DA CONSTRUÇÃO CIVIL
}

\author{
REENGINEER CONCRETE PUMPING MACHINES FOR BUILDING INDUSTRY
}

\author{
Ramilio Ramalho Reis Filho - ramilio.ramalho@ hotmail.com \\ Gerson de Marco - gersondm@yahoo.com \\ Universidade de Araraquara (UNIARA) - SP - Brasil
}

DOI: 10.31510/infa.v16i2.632

\begin{abstract}
RESUMO
O presente trabalho tem como estudo mostrar que a globalização geral não é solução de forma generalizada sem um olhar crítico, devido que cada país tem suas peculiaridades distintas como: tamanho das construções, condições de oferta e demanda, topografia, questões culturais, nos leva a pensar que as empresas multinacionais estão deixando uma brecha no mercado, não respeitando as nossas necessidades. Observando que estas empresas para reduzir custos em projetos, padronizam um produto para mundo inteiro. No caso da construção civil não é diferente, tem no mercado de bombeamento máquinas de 30 a $60 \mathrm{~m}^{3} / \mathrm{h}$ para grandes altura até 100 metros , montada em um reboque ou em cima de caminhões, estes equipamentos são de alto custo, exige-se que o cliente tenha um consumo elevado de concreto, tem-se repensar em máquinas para pequenas alturas até 10 a 20 metros e volume de até $10 \mathrm{~m}^{3} / \mathrm{h}$, onde há uma demanda muito grande.
\end{abstract}

Palavras-chave: Máquinas de Bombear. Capacidade. Adaptação ao Mercado Nacional.

\begin{abstract}
The present paper aim to show that the general globalization is not a generalized solution without a questioning, because each country has its distinct peculiarities as: size of buildings, conditions of supply and demand, topography, cultural issues, leads us to think that multinational companies are leaving a gap in the market, not respecting our needs. Noting that these companies to reduce project costs, standardize a product worldwide. In the case of civil construction not different, in the market of pumping machines of 30 to $60 \mathrm{~m}^{3} / \mathrm{h}$ for large height up to 100 meters, mounted on a trailer or on trucks, these equipments are of high cost, it is required that the customer has a high consumption of concrete, has to rethink in machines for small heights up to 10 to 20 meters and volume up to $10 \mathrm{~m}^{3} / \mathrm{h}$ with a cost in the equipment of maximum $\mathrm{R} \$ 80,000.00$.
\end{abstract}

Keywords: Pumping Machines. Capacity. Adaptation to the National Market. 


\section{INTRODUÇÃO}

Os 5 mais utilizados meios de transportes no Brasil: Rodoviário, Ferroviário, Aéreo, Aquaviário e Dutoviário, O rodoviário é o mais utilizado no Brasil devido a flexibilidade, o que corresponde a $65 \%$ do transporte de carga, as vantagens são: flexibilidade, acessibilidade, agilidade, as desvantagens são: custo elevado, risco de roubos em relação aos meios, acidentes. O transporte ferroviário responde por $20 \%$ da carga, pelo motivo do baixo investimento que o Brasil fez nesta modalidade de transporte, porém o custo com combustível é de $30 \%$ menor em relação rodoviário, vantagens, baixo custo, baixo risco de frutos, produtos variados; Desvantagens, rota fixa, investimentos elevados. O aéreo, vantagens do transporte aéreo: excelente para produtos frágeis, curto prazo de validade, desvantagens: custo elevado, manutenção cara. O aquaviário é feita através de mares, rios e lagos, vantagens: baixo custo, desvantagens: Burocracia afandegária. Dutoviário é feita através de dutos, por sobre a terra, submarinos ou subterrâneos, vantagens, cargas perigosas, baixo custo operacional, longas distâncias, pouca mão de obra, maior volume transportador que os demais meios, desvantagens, rota fixa, alto investimento, não possui flexibilidade (AdmFacil, 2019).

Diante de um cenário competitivo no sistema de transporte, é importante ter conhecimento do produto a ser produzido e suas aplicações, nota-se que o meio de transporte dutoviário tem uma restrição pelo valor do investimento, rota. Segundo o grande volume de obras, são de no máximo 5 andares e volume de $30 \mathrm{~m}^{3}$, faz-se necessário uma bomba de $10 \mathrm{~m}^{3} / \mathrm{h}$ e que seja transportada em uma carroceira de uma camionete, e que esta bomba tenha o valor máximo de $\mathrm{R} \$ 80.000,00$ (AdmFacil, 2019).

O objetivo deste artigo é propor o desenvolvimento de novas máquinas de bombeamento de concreto por meio da reengenharia de produto. Essa nova máquina deverá atender as necessidades de bombeamento de um volume menor de concreto com a finalidade de atender as pequenas construções.

Justifica-se a realização deste estudo porque os atuais equipamentos de bombeamento que se encontram no mercado atendem somente construções que consomem grandes volumes de concreto e seu custo é elevado para as necessidades de pequenas obras civis.

O presente artigo foi organizado da seguinte forma: Na seção 2, é apresentada um referencial teórico sobre conceitos de fabricação de máquinas de bombear concreto. A seção 3 descreve o método de pesquisa adotado para este artigo. A Seção 4 e 5, apresentam o 
desenvolvimento da proposta para uma máquina de bombear concreto e as considerações finais, respectivamente.

\section{FUNDAMENTAÇÃO TEÓRICA}

Todas as máquinas são compostas de sistemas: mecânicos, elétricos, hidráulicos e eletrônicos tem como objetivo produzir um trabalho, para cada trabalho existe uma máquina indicada para esta tarefa, que está relacionada com a segurança, custo, manutenção, prazo e facilidade de manuseio.

\subsection{Fundamentação em Mecânica dos Fluídos}

A palavra hidráulica provê do grego: hydra, que significa água, e aulos, significa cano. a hidraúlica estuda as caracteristicas dos fluidos em estado em ambiente limitado.

Para construir máquinas de bombeamento de fluidos, é necessário conhecer mecânica dos fluidos como: viscosidade dinâmica, viscosidade cinética, pressão, a teoria da continuidade, energia, vazão e elementos de máquinas.

Desde a antiguidade o homem se serviu de máquinas de bombeamento com objetivo o abastecimento de água para fins de necessidades humanas. Só no seculo XVII , o francês Pascal fez estudos com fluidos onde percebeu a relação de pressão, força e área, sendo que pressão é igual a força dividida pela área.

Segundo Streeter (1977, p.20), a pressão é calculada dividindo-se a força normal que age contra uma superfície. A pressão num ponto é o limite da relação entre a força normal e área, quando se fizer a área tender a zero toda a região terá a mesma pressão em todas as direções.

Segundo Streeter (1977, p.110), a lei de continuidade de um sistema permanece constante todo o tempo na equação $\mathrm{dm} / \mathrm{dt}=0$ onde $\mathrm{m}$ é a massa total, onde o volume/tempo=vazão permanece constante em todo o circuito, também pode-se descrever como, a área transversal da tubulação multiplicado pela velocidade do fluido $Q=A . V$ ou $Q=V$ (volume)/T(tempo).

Segundo Streeter (1977, pag.5) entretanto, as pesquisa de Issac Newton visa dimensionar a tensão de cisalhamento de um fluido, onde a uma relação entre a viscosidade dinâmica , cinética e densidade do fluido, onde viscosidade dinâmica $\mu=\gamma . \vartheta$, sendo que $\mu=$ viscosidade dinâmica $; \gamma=$ densidade $; \vartheta=$ viscosidade cinética. Isto pode ser aplicado para 


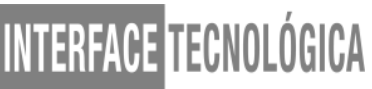

dimensionar a tensão de cisalhamento de um fluído, onde $\zeta=\mu . \mathrm{V} / \xi$ onde $\zeta=$ tensão de cisalhamento; $\mu=$ viscosidade dinâmica $; V=$ velocidade do fluído ; $\xi=$ espessura do fluído.

Segundo Drapinski (1977, p.6), a aplicação direta em meios práticos destas teorias, em sistemas hidráulicos e pneumáticos, acrescentando-se as equações importantes, para o cálculo da potência do motor para acionamento da máquina, expressa: $\mathrm{P}=\mathrm{p} \cdot \mathrm{Q} / \eta \cdot 450$, onde $\mathrm{P}=$ potência em cavalo vapor; $\mathrm{p}=$ pressão em $\mathrm{Kgf} / \mathrm{cm}^{2} ; \eta=$ rendimento de $80 \% ; 450=$ fator de conversão para cavalo.

Para dimensionar o diâmetro da tubulação segundo Drapinski (1977), a velocidade recomendada do fluído são: $6 \mathrm{~m} / \mathrm{s} ; 3 \mathrm{~m} / \mathrm{s} ; 1 \mathrm{~m} / \mathrm{s}$, respectivamente pressão; retorno e sucção, Segundo Streeter $(1977$, p.110) a lei da continuidade apresentada, onde $Q=A . V$, pode se concluir que $\mathrm{A}=\mathrm{Q} / \mathrm{V}, \mathrm{A}=\mathrm{a}$ área de passagem do fluído, sendo a tubulação circular, a área respectiva do diâmetro interno por onde passa o fluido é igual: $A=\llbracket\left[\mathrm{d}^{2} / 4\right.$, por consequência: $\mathrm{d}=$ $(4 . \mathrm{A} / \mathrm{II})^{\wedge} 2$

Segundo catálogo Festo (2001), os componentes para uso em circuitos hidráulicos e pneumáticos são: bombas, válvulas de controles direcionais, atuadores lineares, atuadores rotativos, acumuladores hidráulicos e pneumáticos, filtros, manômetros, válvulas de retenções, mangueiras e reservatórios de fluidos hidráulicos.

\subsection{Fundamentação em Circuitos Elétricos}

Segundo Carron e Guimarães (2003, p.213), a definição de corrente elétrica é a razão entre voltagem pela resistência, ou seja: $\mathrm{I}=\mathrm{U} / \mathrm{R}$, o aonde: $\mathrm{I}=$ corrente em Ampére; $\mathrm{U}=$ voltagem em Volts; $\mathrm{R}=$ resistência em ohms. A potência de um circuito elétrico; $\mathrm{P}=\mathrm{U}$.I ; onde $\mathrm{P}=$ potência em Watts; $U=$ diferencia de potencial em Volts : I = corrente em Ampére.

Carron e Guimarães (2003, p.238), menciona-se os componentes elétricos básicos, tais: resistores, indutores, capacitores, diodos e transistores. Cada componente tem uma função nos circuitos elétricos e eletrônicos, como: indutores pode-se produzir um relé; capacitor para eliminar correntes parasitas, resistores para queda de tensões, diodos para retificar uma corrente alternada, transistores para ampliar um sinal, ou seja, um ganho de corrente, funciona como um transformador.

Segundo o Manual Festo (2001) de sistemas eletropneumáticos, os relés são usados para processamento de sinais e também para o controle remoto de circuitos que transportam altas correntes. 
Na prática as características de um relé deve ter: baixa manutenção, elevado número de manobras e baixo tempo de respostas, observa-se que o relé é composto de uma bobina (indutor).

\subsection{Fundamentação em Mecânica}

Segundo Provenza (1991, p.11), a mecânica é constituída por três partes: primeiro a cinemático, que estuda os movimentos independente das causas que isto ocorreu; segundo a estática, que estuda o equilíbrio das forças sobre um corpo em repouso; terceiro a dinâmica que estuda o movimento dos corpos em relação às forças que atuam sobre o corpo.

A equação $\mathrm{F}-(\mathrm{m} . \mathrm{a})=0$, demonstra as força estão em equilíbrio, Essa expressão nos mostra que há um equilíbrio entre a força motora e a força de inércia. Este princípio foi anunciado D'Alembert, nos permite resolver os problemas dinâmico como se fosse estáticos.

Segundo Stipkovic (1977, p.19), pode-se variar a velocidade angular através de engrenagens tal que: $n 1 . z 1=n 2 . z 2$, onde $n 1$ é a rotação do eixo motor, $\mathrm{z} 1$ é a engrenagem montada neste eixo é igual a n2 rotação no eixo movido e Z2 é a engrenagem montada no eixo 2. Se $\mathrm{Z} 1$ tiver 15 dentes e $\mathrm{Z} 2$ com 30 dentes a rotação se metade do eixo, mas o torque no eixo 2 será duas vezes maior que no eixo 1 , isto permite reduzir a velocidade e aumentar a força de tração.

Segundo Carron e Guimarães (2003, p. 30), o mesmo ocorre quando se tem uma transmissão por correia o $\mathrm{n} 1 . \mathrm{d} 1=\mathrm{n} 2$.d2 onde $\mathrm{n} 1$ é a rotação no eixo 1 e d1 diâmetro da polia motora é igual rotação no eixo 2 e d2 é o diâmetro primitivo da polia 2.

De acordo com Holbrook (1976, p.12), São dispositivos onde pode se alterar movimentos circulares em movimentos lineares, segundo o desenho abaixo (Figura 1):

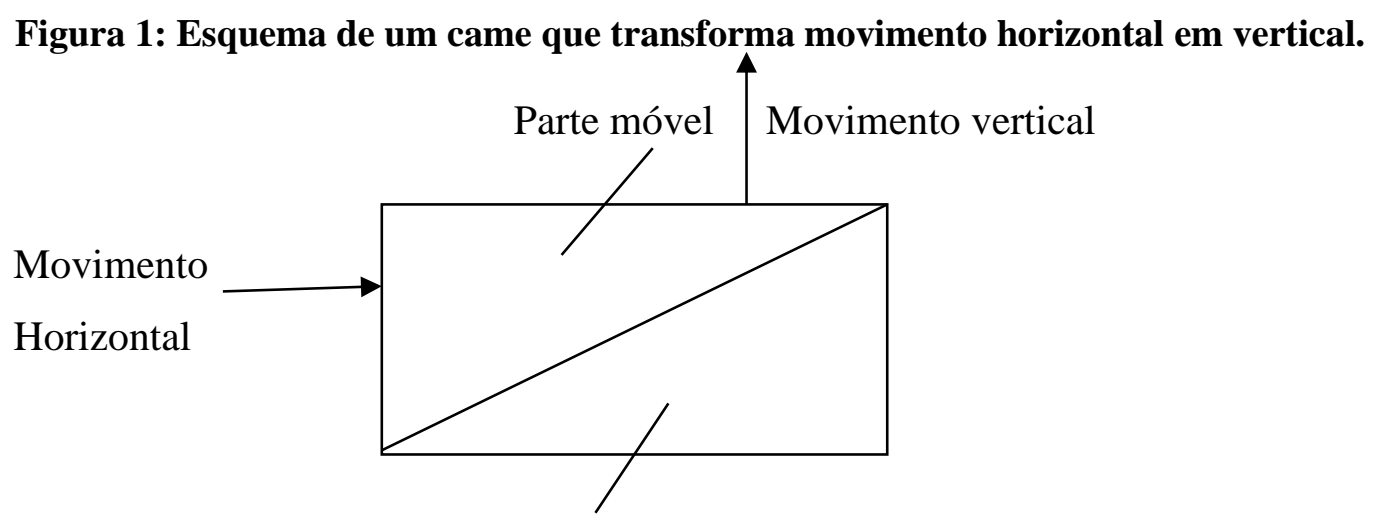

Parte fixa

Fonte: Adaptado pelo autor a partir de Holbrook (1976) 
Pode-se alterar um movimento horizontal em um movimento vertical, igual duas cunhas sobre postas, a debaixo móvel e superior fixa no eixo x, só pode movimentar no eixo Y, conforme Figura 1.

Todos os componentes mecânicos precisam-se de elementos de máquinas como: parafusos, rolamentos, polias, retentores, buchas e proteção de correias chavetas.

Segundo Nash (1976, p.1) a resistências dos materiais vem de longa data. Desde a Grécia antiga, já havia essa preocupação, passando por Leonard da Vinci, Galileo, Jacob Bernouilli, Hooke, Leonard Euler, Coulomb e Navier.

O que importa na mecânica dos sólidos, são os seis tipos de esforços realizados: tração, compressão, torção, flexão, cisalhamento e flambagem. Pode-se ter solicitações combinadas como flexo-torção, compressão e flambagem e assim por diante.

\subsection{Máquina de Bombear Concreto Atual}

Conforme esquema hidráulico e elétrico (Figura 2) pode-se notar que as máquinas existentes no mercado, tem um número muito grande de componentes. Isto acarreta em custo muito elevado na construção. Também deve-se observar a parte mecânica, onde a caixa de água, é um componente caro. Há ainda a exigência de um controle dimensional e geométrico de microns de metro na construção, tornando um componente de custo elevado.

Figura 2: Esquema elétrico e hidráulico da máquina atual
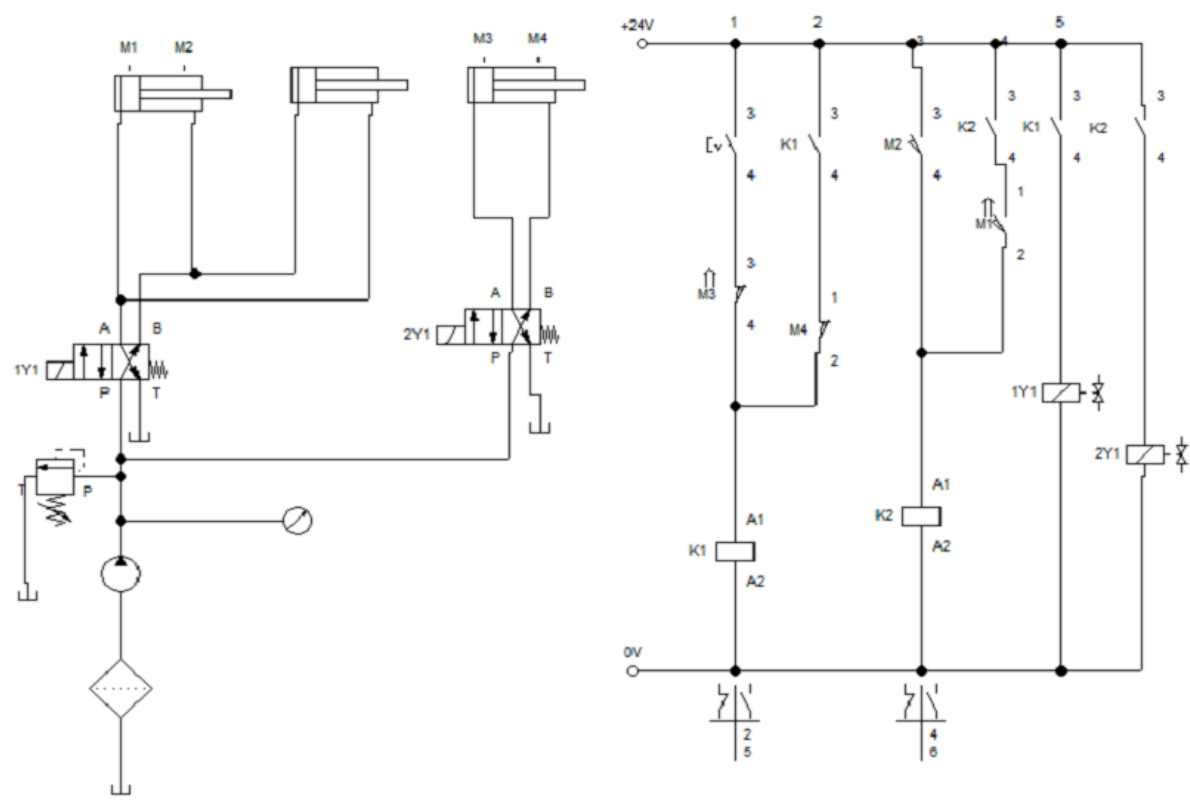

Fonte: Elaborado pelo autor (2019) 
A manutenção é outro problema que afeta o custo, pois na hora do reparo de qualquer componente, exige-se alinhamento preciso das peças mecânicas. A Figura 2 apresenta o modelo elétrico e hidráulico das máquinas atuais. Na parte hidráulica, ela é composta por: (1) tanque, (2) filtro, (3) bomba, (4) manômetro, (5) válvula de alívio, (6) válvula de controle direcional e (7) cilindro hidráulico. Na parte elétrica, ela é composta por: (1) botoeira, (2) relé, (3) fim de curso e (4) solenóide.

A Figura 3 apresenta o funcionamento de uma máquina de bombeamento, consiste de 2 cilindros hidráulicos (1) e (2) funciona de modo, quando um cilindro avança o outro retrai; o cilindro (8) muda a válvula (7), direcionando o concreto, Tem dois cilindros de transferência (4) e (5) por onde concreto é aspirado da caçamba (6) por um dos cilindros hidráulicos e empurrado pelo o outro, A parte elétrica funciona da seguinte forma , quando aciona a botoeira (1) ativa o relé (2) K1, e este por consequência aciona o solenoide da válvula 1Y1, acionando o cilindro hidráulico (1) e (2); avançando o (1) e retraindo (2), quando o cilindro (1) chega no fim de curso aciona o a chave de fim de curso (3) M2, este por consequência aciona o relé (2) K2 e o solenoide (4) 2Y1 da válvula, movimenta o cilindro(8) e muda a posição da válvula (7).

\section{Figura 3: Visão mecânica da máquina}

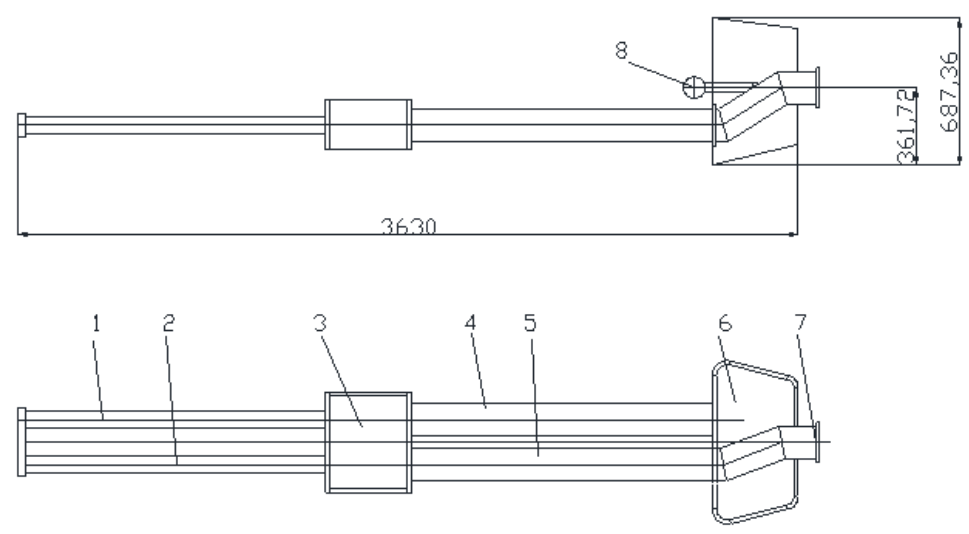

Fonte: Elaborado pelo autor (2019)

\section{METODOLOGIA DE PESQUISA}

Para a condução deste trabalho, foi utilizada a pesquisa bibliográfica. Segundo Lakatos (2009), tem como objetivo apresentar uma visão geral sobre o que já foi investigado na área. Além disso, também foi utilizada a pesquisa de campo, que valoriza a observação direta, 
indireta ou participativa. Neste método, deve-se observar como os fatos e fenômenos acontecem, e posteriormente analisá-los, interpretá-los e relacioná-los com a fundamentação teórica.

\section{PROPOSTA PARA MÁQUINA DE BOMBEAR CONCRETO}

Conforme esquema hidráulico e elétrico (Figura 4), pode-se notar que a máquina proposta, tem um menor número de componentes, isto acarreta em um menor custo na construção, observa-se a parte mecânica, onde não há caixa de água, a parte do esquema hidráulico e elétrico, também tem uma quantidade reduzido de relé, cilindro hidráulico, válvulas e acrescentado o came de acionamento da válvula, outro ponto é que as peças são de tamanho menor, já que proposta é apresentar uma máquina de fácil transporte e que bombeia até $10 \mathrm{~m}^{3} / \mathrm{h}$ , até 5 andares.

A manutenção da máquina proposta, reduziu-se o número de peças e por consequência a manutenção, A figura 4 apresenta o modelo elétrico e hidráulico da máquina proposta. Na parte hidráulica, ela é composta por: (1) tanque, (2) filtro, (3) bomba, (4) manômetro, (5) válvula de alívio, (6) válvula de controle direcional e (7) cilindro hidráulico. Na parte elétrica, ela é composta por: (1) botoeira, (2) relé, (3) fim de curso e (4) solenóide.

Figura 4: Esquema elétrico e hidráulico da máquina proposta pelo autor
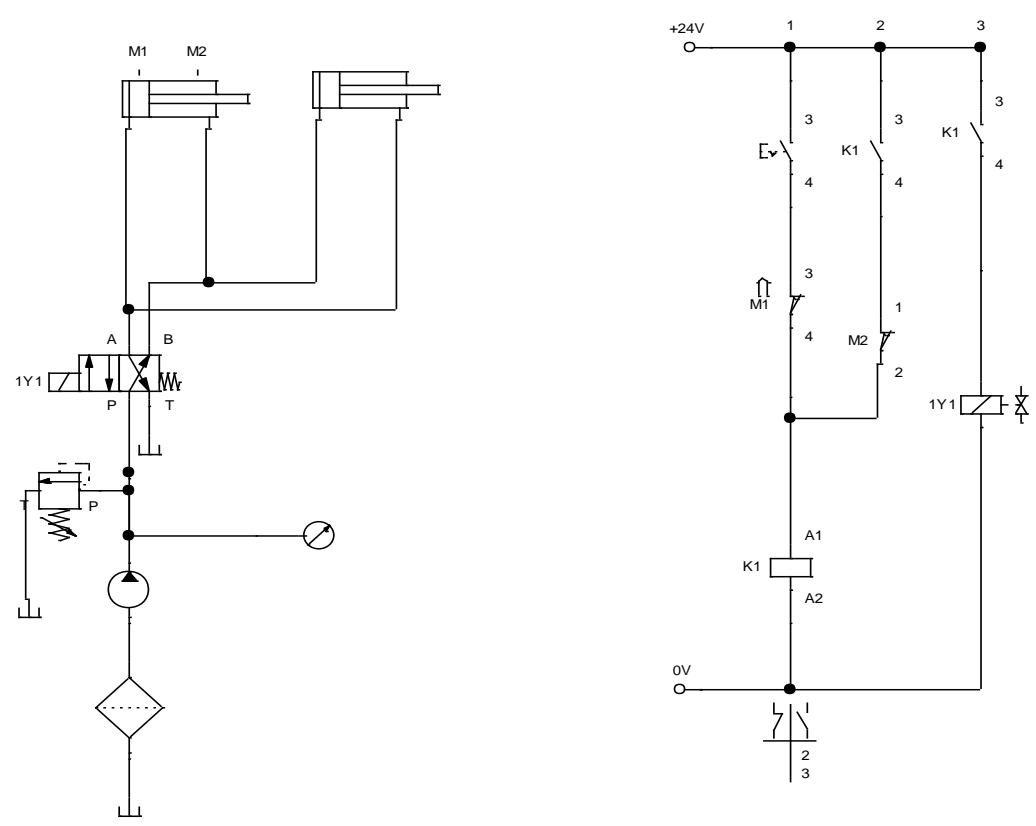

Fonte: Elaborado pelo autor (2019) 
A figura 5 mostra o funcionamento da máquina de bombeamento proposta: consiste de 2 cilindros hidráulicos (1) e (2) que funciona de modo, quando um avança o outro retrai; o came (6) muda a válvula (5), direcionando o concreto. Tem dois cilindros de transferência (3) e (4) por onde concreto é aspirado da caçamba por um dos cilindros hidráulicos e empurrado pelo o outro, A parte elétrica funciona da seguinte forma , quando aciona a botoeira (1), ativa o relé (2) $\mathrm{K} 1$, e este por consequência aciona o solenoide da válvula $1 \mathrm{Y} 1$, acionando o cilindro hidráulico (1) e (2); avançando o (1) e retraindo (2), quando o cilindro (1) chega no fim de curso aciona o a chave de fim de curso (3) M2, este por consequência desarma o relé (2) K1 e o solenoide (4) 1Y1 da válvula, fazendo o movimento inverso dos cilindro(1) e (2), muda a posição da válvula (5) através do came (6).

\section{Figura 5: Visão mecânica da máquina proposta pelo autor}

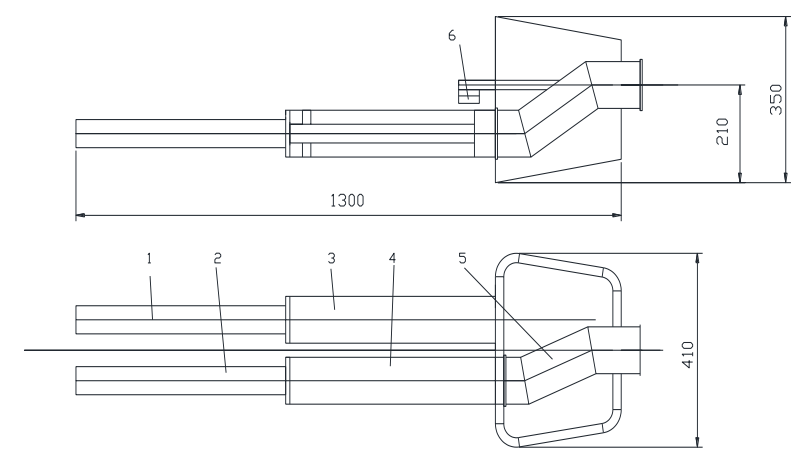

Fonte: Elaborado pelo autor (2019)

\section{CONSIDERAÇÕES FINAIS}

O desenvolvimento dessa nova máquina levou em consideração as especificidades locais relacionadas a construção civil, uma vez que, as grandes empresas transnacionais desenvolvem equipamentos voltados para grandes obras, deixando de lado as pequenas construções. Observando que estas empresas para reduzir custos em projetos, padronizam um produto para mundo inteiro. No caso da construção civil, tem no mercado de bombeamento máquinas de bombeamento de 30 a $60 \mathrm{~m}^{3} / \mathrm{h}$ montada em um reboque ou em cima de caminhões. Estes equipamentos são de alto custo, exige-se que o cliente tenha um consumo elevado de 
concreto. Se o cliente tiver uma obra que irá gastar $10 \mathrm{~m}^{3}$ de concreto, o preço da bomba só para sair da usina de concreto custa é de $\mathrm{R} \$ 700,00$, mais o custo do concreto por $\mathrm{m}^{3} / \mathrm{h}$ bombeado. Sabendo que o custo médio de concreto usinado é de $\mathrm{R} \$ 220,00$ o $\mathrm{m}^{3}$. Para viabilizar o uso do equipamento e a sua capacidade é necessário ter várias pequenas construções na cidade para justificar o deslocamento desse equipamento. A solução é fazer uma reengenharia nos equipamentos, porém não é miniaturizar, porque o custo não é proporcional pelo fato dos componentes ter valores em função do tamanho dos lotes fabricados. O país pode adotar uma política pública de incentivos ao desenvolvimento tecnológico, para dessa forma conseguir novos equipamentos mais apropriados as necessidades de sua população.

\section{REFERÊNCIAS}

ADMFACIL. Tipos de Transportes: Vantagens e Desvantagens. Acessado em: 14 de abril de 2019. Disponível em: <http://www.admfacil.com/tipos-transportes/.

CARRON, Wilson e GUIMARÃES, Osvaldo. Física. 2a ed. São Paulo: Editora Moderna Ltda , 2003, p.338.

DRAPINSKI, Janusz, Sistemas Hidráulicos e Pneumáticos, 3 a ed. São Paulo, Editora Diretório Acadêmico Centro Paula Souza,1977, p.42.

FESTO, Automação, Sistemas Eletropneumáticos e Hidráulicos. ed Abril/2001 São Paulo,p.168.

FESTO, Automação, Sistemas Eletropneumáticos e Hidráulicos Software. ed Abril/2001 São Paulo,p.168.

HOLBROOK, L. Horton, Manual Técnico para Desenhistas e Projetistas de Máquinas. 8a ed. São Paulo: Hemus Livraria Editora Ltda , 1976, p. 428

NASH, William Arthur, Resistência dos Materiais. 11a ed . São Paulo:Editora Mc Graw-Hill do Brasil Ltda, 1976, p.384.

PROVENZA, Francesco, Mecânica Aplicada. 2a ed. São Paulo: Editora F. Provenza, 1991, p.433.

STIPKOVIC, Marco Filho. Engrenagens. 2a ed. São Paulo: Editora Mc Graw-Hill do Brasil Ltda, 1973, p.138.

STREETER, Victor Lyle. Mecânica dos Fluídos. 1a ed. São Paulo: Editora Mc Graw-Hill do Brasil Ltda, 1977, p.736. 